\section{Cureus}

\title{
Traumatic Lumbar Interdural Cyst with Intradural Expansion and Compression of the Cauda Equina: Case Report and Surgical Video
}

Salah G. Aoun ${ }^{1}$, Aaron R. Plitt ${ }^{1}$, Tarek Y. El Ahmadieh ${ }^{1}$, Mazin Al Tamimi ${ }^{1}$, Tony Whitworth 1

1. Neurosurgery, University of Texas Southwestern Medical Center, Dallas, USA

$\square$ Corresponding author: Salah G. Aoun, salahaoun@hotmail.com

Disclosures can be found in Additional Information at the end of the article

\section{Abstract}

Intradural arachnoid cysts are common entities that can be congenital, or caused by infectious, inflammatory, or even traumatic processes. However, true "inter"-dural cysts formed between the two lamellae of the lumbar dura without any fistulous arachnoid connection are rare. We present the case of a post-traumatic interdural cyst formation of the lumbar spine that compressed the roots of the cauda equina causing acute unrelenting pain. The cyst walls were formed by the true dural layers, and the cavity was filled with blood degradation products without any arachnoid connection to the subdural space. A commented video that details the diagnostic and surgical aspects of this case, alongside intraoperative footage is provided.

Categories: Neurosurgery, Trauma

Keywords: intradural cyst, interdural cyst, cauda equina compression, traumatic spine cyst, surgical video

\section{Introduction}

Intradural cyst of the spinal cord usually consist of spinal fluid-filled diverticula that can be found incidentally, or result in the compression of the nerve roots of the cauda equina, or of the spinal cord itself. While some can be congenital, other etiologies include inflammatory or infectious processes, or even traumatic events [1-3]. These events usually result in folds and adhesions in the arachnoid layer, or in a ball-valve phenomenon through an arachnoid fistula that can generate large bubbles, and compress the functional intradural components. However, a true cystic formation between the dural layers, also called interdural cyst, is very rare, with a handful of cases described in the literature [3-7]. To our knowledge there has only been one instance of traumatic interdural cyst that was reported in the literature, but that was due to a fistulous connection with the arachnoid layer of the nerve root sleeve. We report a case of post-traumatic lumbar interdural cyst that likely resulted from a hematoma formation between the two dural layers and required surgical drainage and marsupialization.

\section{Case Presentation}

A previously healthy 37-year-old man experienced an acute onset of back pain radiating to bilateral S1 territories after a soccer match while bending over to tie his shoes. His pain worsened over the course of 6 months which prompted a magnetic resonance scan (MRI). The MRI showed a cystic lesion ventral to the thecal sac at L4-5 which was compressing the roots of

How to cite this article

Aoun S G, Plitt A R, El Ahmadieh T Y, et al. (June 04, 2019) Traumatic Lumbar Interdural Cyst with Intradural Expansion and Compression of the Cauda Equina: Case Report and Surgical Video. Cureus 11(6): e4824. DOI 10.7759/cureus.4824 


\section{Cureus}

the cauda equina (Figure 1).

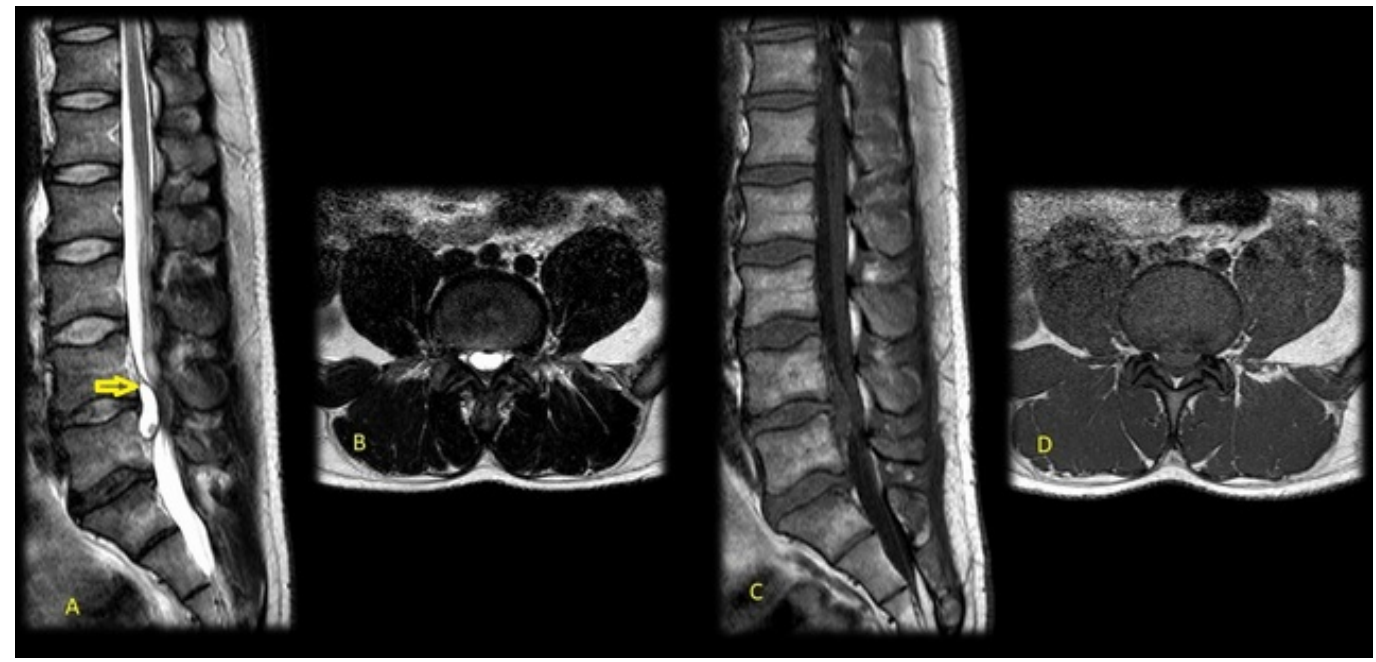

FIGURE 1: Preoperative Magnetic Resonance Imaging of the Lumbar spine

A: Sagittal T2 sequence, B: Axial T2 Sequence, C: Sagittal T1 sequence D: Axial T1 sequence

This magnetic resonance imaging sequence shows a lesion (yellow arrow) that is hyperintense on $\mathrm{T} 2$ sequences and isointense on $\mathrm{T} 1$, with contents that resemble spinal fluid.

He was taken to the operating room, where a midline durotomy revealed a bulging cystic mass compressing the nerve roots (Video 1).

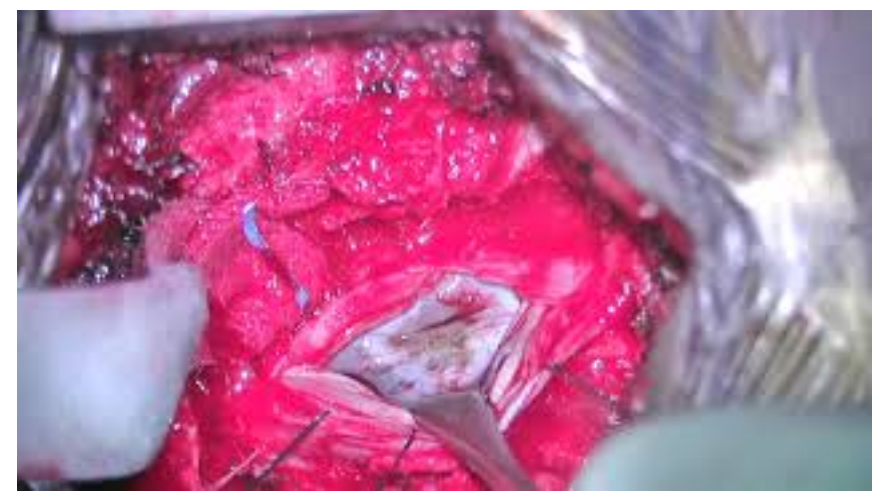

\section{VIDEO 1: Operative Video}

Operative video showcasing the clinical case, imaging characteristics, and intra-operative surgical resection footage of the lumbar spinal cyst

View video here: https://www.youtube.com/watch?v=DXznmz4xgNw\&t=4s

The mass appeared to be intradural. It did not originate from the disc space and had no ventral tract or fistulous connection. The wall of the cyst was sharply opened and had the consistency and feel of dura. The cyst was filled with motor-oil fluid that resembled the old blood. The cavity was lined with fibrous material that was sent for pathology with part of the wall (Figure 2). 


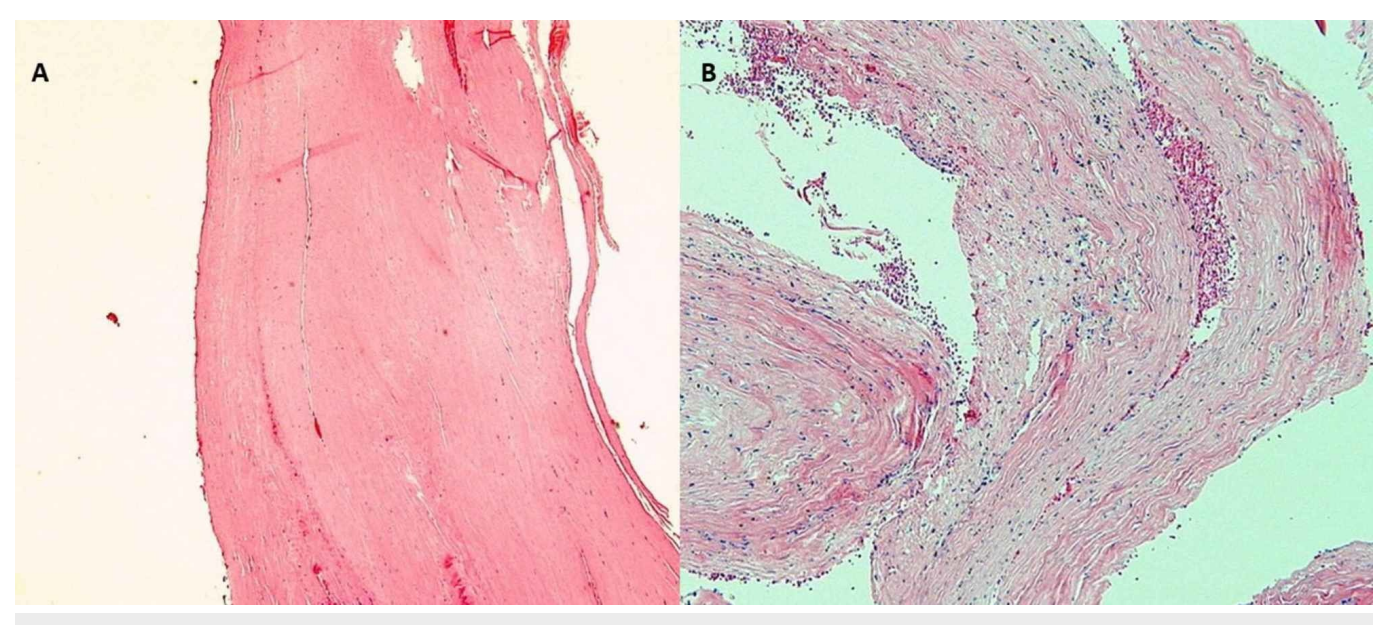

FIGURE 2: Pathology Slides of the Resected Lumbar Cyst

A: Hematoxylin Eosin slide showing the cyst wall which was consistent with collagenous tissue forming dura

B: Hematoxylin Eosin slide showing the content of the cyst which was consistent with fibrous connective tissue and blood

The cyst was completely marsupialized and then cauterized. The patient did well after surgery and was discharged home on post-operative day two neurologically intact. His symptoms were completely resolved.

\section{Discussion}

True interdural cysts of the spinal cord are rare entities [3]. Inflammation or infection can result in arachoiditis with the resulting sequestration of the spinal fluid in chambers that can grow and expand with time. On the other hand, traumatic injury of the spine can result in the avulsion of the neural tube at the level of the nerve root sleeves, and lead to intradural arachnoid cyst formation, or even interdural expansile spaces, but these are usually the product of a fistulous arachnoid connection. In our patient, there was no evidence of a connection diverting spinal fluid from the intradural space to the cyst. The cyst was also perfectly formed by leaflets of the dura, and was filled with motor-oil fluid and had traces of hemosiderin, which led us to believe that the trauma caused by trunk flexion must have ruptured a small dural vessel, leading to the formation of an acute hematoma between the ventral dural lamellae. We elected to fenestrate the cyst widely and cauterize its contents to prevent the creation of a oneway spinal fluid valve leading to the recurrence of the cyst, or the herniation and sequestration of the nerve roots of the cauda equina into the dural pouch which could lead to neurological deficits.

\section{Conclusions}

This is the first report of a traumatic lumbar interdural cyst with compression of the cauda equina roots. Treatment of these lesions requires careful dissection of the intradural space. Adequate cyst fenestration is required in order to prevent recurrences.

\section{Additional Information \\ Disclosures}

Human subjects: Consent was obtained by all participants in this study. UTSW Institutional 
Review Board issued approval NA. This Case report was written in compliance with our institutional ethical review board IRB approval and patient consent was waived in light of the retrospective and de-identified nature of the data presented in accordance with the UTSW IRB. . Conflicts of interest: In compliance with the ICMJE uniform disclosure form, all authors declare the following: Payment/services info: All authors have declared that no financial support was received from any organization for the submitted work. Financial relationships: All authors have declared that they have no financial relationships at present or within the previous three years with any organizations that might have an interest in the submitted work. Other relationships: All authors have declared that there are no other relationships or activities that could appear to have influenced the submitted work.

\section{References}

1. Rabb CH, McComb JG, Raffel C, Kennedy JG: Spinal arachnoid cysts in the pediatric age group: an association with neural tube defects. J Neurosurg. 1992, 77:369-372.

10.3171/jns.1992.77.3.0369

2. Agnoli AL, Schonmayr R, Laun A: Intraspinal arachnoid cysts. Acta Neurochir (Wien). 1982, 61:291-302. 10.3171/jns.1992.77.3.0369

3. Sajjad J, Yousaf I, Bermingham N, Kaar G: Interdural spinal cyst: a rare clinical entity . World Neurosurg. 2016, 88:688-689. 10.1016/j.wneu.2015.11.051

4. Lee JH, Jung TG, Kim HS, Jang JS, Lee SH: Symptomatic isolated lumbar interdural arachnoid cyst. Neurol Med Chir (Tokyo). 2010, 50:1035-1038. 10.1016/j.wneu.2015.11.051

5. Chen HJ, Chen L: Traumatic interdural arachnoid cyst in the upper cervical spine. Case report . J Neurosurg. 1996, 85:351-353. 10.3171/jns.1996.85.2.0351

6. Done SL, Hayman LA, New PF, Davis KR, Chapman PH: Interdural cyst of the lumbosacral region. Neurosurgery. 1984, 14:287-294. 10.1227/00006123-198403000-00005

7. Cilluffo JM, Gomez MR, Reese DF, Onofrio BM, Miller RH: Idiopathic ("congenital") spinal arachnoid diverticula. Clinical diagnosis and surgical results. Mayo Clin Proc. 1981, 56:93-101. 10.1227/00006123-198403000-00005 